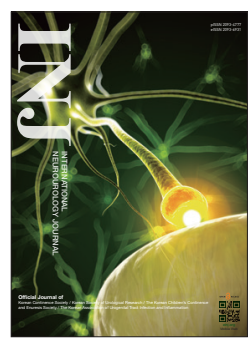

\title{
Artificial Urinary Sphincter for Postradical Prostatectomy Urinary Incontinence - Is It the Best Option?
}

\author{
Yun-Sok $\mathrm{Ha}^{1,2}$, Eun Sang Yoo \\ ${ }^{1}$ Department of Urology, School of Medicine, Kyungpook National University, Daegu, Korea \\ ${ }^{2}$ Joint Institute for Regenerative Medicine, Kyungpook National University, Daegu, Korea
}

\begin{abstract}
Male stress urinary incontinence (SUI) can undoubtedly reduce quality of life and promote personal distress and psychosocial alienation. The frequency of postprostatectomy urinary incontinence (PPI) counts on the characterization of urinary incontinence and the periods of patient follow-up. Operational therapeutics, for instance, urethral male slings and artificial urinary sphincters, are well-chosen as adequate and secure surgeries for male SUI in men with continual PPI when conservative treatment is ineffective. Over the former 2 decades, surgery has progressed regarding both operative approach and sling architecture. However, there are no guidelines about when surgery should be carried out and which is the most appropriate surgical option. In this review, we summarize recent advances in implantable devices for PPI and also discuss traditional surgical care. When we are planning the male PPI surgery, careful preoperative work-up should be performed and surgical method should be chosen according to the severity of the disease. Male sling is preferred in mild and moderate symptomatic patients with normal detrusor pressure and it is recommended to select traditional artificial urinary sphincter device in those with severe symptoms. It is expected that effective devices without adverse events will be developed with technical advances in near future.
\end{abstract}

Keywords: Urinary sphincter, artificial; Male sling; Postprostatectomy incontinence; Urinary incontinence, stress

- Fund/Grant Support: This research was supported by the Basic Science Research Program through the National Research Foundation of Korea (NRF) \& funded by the Korean government (MSIT) (2019R1H1A1079839).

- Conflict of Interest: No potential conflict of interest relevant to this article was reported.

\section{INTRODUCTION}

Urinary incontinence (UI) affects approximately $15 \%-20 \%$ of patients after radical prostatectomy (RP), with a considerable influence on the quality of life and emotional well-being of individuals [1]. Given the long period of existence after RP for localized prostate cancer, a lot of men fall ill with postradical prostatectomy urinary incontinence (PPI) for decades [2,3]. Several options are available for treatment, together with behavioral therapy, pelvic floor muscle exercises, injection of bulking agents, and the insertion of prosthetics (i.e., urethral male slings [MS]) or compressive devices (i.e., artificial urinary sphincters [AUS]) [4]. In a recent Swedish, population-based, nationwide study, 3\% of men who experienced RP afterwards received PPIcorrection surgery, showing that serious UI cannot be considered as a "rare adverse event" [5]. However, there is a lack of consensus about the definition of severe UI [6]. In the Ontario Health Insurance Plan Register, 3\% of men who had experienced RP had encountered PPI operation within a median of 3 years after RP [7]. According to US SEER (Surveillance, Epide-

Corresponding author: Eun Sang Yoo (iD https://orcid.org/0000-0002-7442-6886 Department of Urology, Kyungpook National University Hospital, School of Medicine, Kyungpook National University, 680 Gukchaebosang-ro, Jung-gu, Daegu 41944, Korea

E-mail: uroyoo@knu.ac.kr / Tel: +82-53-0-5851 / Fax: +82-534-21-9618

Submitted: October 14, 2019 / Accepted after revision: December 13, 2019 
Table 1. Summary of efficacy and complications in commercially available synthetic male slings (MS) and artificial urethral sphincter (AUS) devices

\begin{tabular}{lcl}
\hline Instrument & Overall success rate (\%) & \multicolumn{1}{c}{ Complications } \\
\hline $\begin{array}{l}\text { Male sling } \\
\text { Adjustable MS }\end{array}$ & & \\
$\quad$ Argus sling & $62-100$ & $\begin{array}{l}\text { Urgency, urethral erosion, perineal pain, and infection } \\
\text { Bladder perforation, hematoma, infection, and urethral erosion }\end{array}$ \\
Remeex sling & $85-90$ & Wound infection, perineal pain, urethral injury, and urinary retention \\
ATOMS sling & $38.9-92.3$ & \\
Nonadjustable MS & & Perineal pain, urinary retention, and urgency \\
AdVance sling & $62.5-89.4$ & Wound dehiscence, perineal discomfort, and urinary retention \\
Virtue sling & $32-41.9$ & Corporal carvernosal injury and chronic pain \\
I-STOP TOMS & $22-87$ & \\
AUS device & & Infection, cuff erosion, and urethral atrophy \\
AMS 800 & $44-86.4$ & Mechanical failure, infection, and pump perforation \\
FlowSecure device & $54-97$ & Device defect, infection, chronic pain, and urethral erosion \\
Zephyr ZSI 375 & $30-58$ & Balloon migration, pain, and infection \\
Pro-ACT & $67-70$ & Urethral erosion and rectourethral fistula \\
Periurethral constrictor & $72.3-79$ & \\
\hline
\end{tabular}

miology and End Results)-Medicare data, 6\% of patients who experienced RP from 2007-2010 were subjected to a PPI surgery after a median of 20 months [8]. Nonetheless, most studies suggested that PPI surgery remained underused.

Sphincter implants, especially AUS, are designated in patients with moderate-to-severe UI not susceptible to conservative regimen, although they are expensive and have a high rate of re-do procedure [9]. MS can be split into adjustable or nonadjustable types and offer a charming choice for men who hope to keep away from mechanical acting in the time of urinary voiding [10]. Over the past 2 decades, this procedure has progressed regarding both surgical method and sling style, and numerous devices are currently usable that have diverse mechanisms of action. The selection of device, however, should be figured out in line with patient circumstances. The best surgical treatment relies upon different patient-related factors, including the severity of urine leakage (as evaluated by diaper weight), bladder contractility, urethral compliance, a history of radiation therapy (RT), or previous incontinence procedure, and most patients require a urodynamic study. There is no established standard definition for the severity of PPI or selection of operational procedure, notwithstanding most experienced surgeons assent that patients with mild-to-moderate PPI should undergo MS, while those who suffer from severe PPI need AUS implantation [11].

An AUS retroluminal sling or quadratic sling may be the most suitable selection for an appropriate patient, depending on distinct urodynamic findings. Evolution in this area goes on and a number of novel instruments are in progress. In this re- view, we describe the technologic advances in surgical instruments for male PPI. A broad review of all publications related to PPI, MS, and AUS devices has been performed. Table 1 summarizes the instruments introduced in the present article.

\section{MALE SLINGS}

Over the past few years, the number of MS available for PPI has increased dramatically. Synthetic MS for recent PPI are gaining popularity because they avoid the need for mechanical manipulation when voiding and their costs are relatively low. Most experienced urologists concur that an appropriate choice of patient is key to favorable MS outcomes [12]. The most appropriate patients have mild-to-moderate SUI and competent residual sphincter function, which permits sufficient detrusor contraction to overwhelm the fixed sling impediment and allow voiding [13]. Given the option between MS and AUS, most PPI patients choose lesser invasive MS rather than AUS [14]. From the patient's context, there is no interval for healing to happen before device activation. Patients can void without device manipulation, and continence rates can be significantly and instantly improved after catheter removal. Regarding device design, MS are not circumferential occlusion devices; accordingly, the risks of urethral atrophy and erosion are rare compared to AUS [14].

MS are classified into 2 types: adjustable and nonadjustable. Depending on the method of operation, they are divided into retropubic and transobturator types. Adjustable MS available 

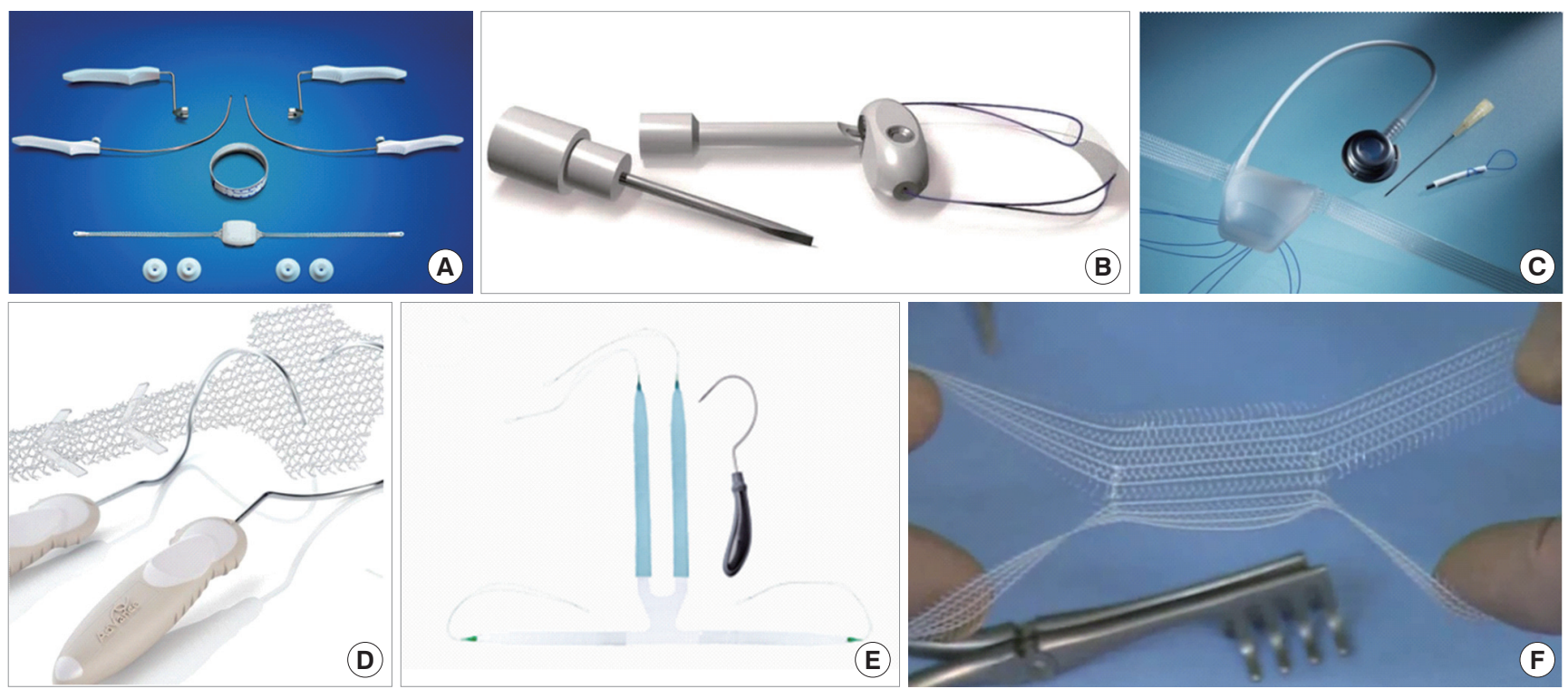

(D)

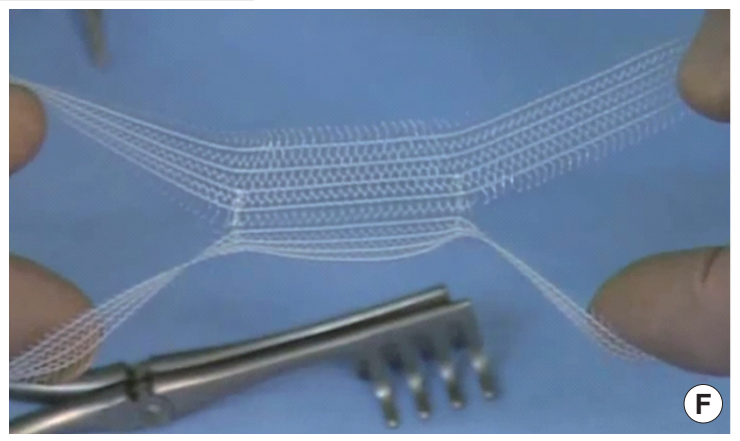

Fig. 1. Representative pictures of the various male sling (MS) devices. (A) Argus sling; (B) Remeex sling; (C) ATOMS sling; (D) Advance sling; (E) Virtue sling, and (F) I-STOP TOMS.

commercially are Argos (Promedon, Cordoba, Argentina), ReMeex (Neomedic, Barcelona, Spain), and ATOMS (AMI, Feldkirch, Austria), while current nonadjustable MS are AdVance (Boston Scientific, Minnetonka, MN, USA), I-STOP TOMS (CL Medical, Lyon, France), and Virtue (Coloplast, Minneapolis, MN, USA) sling. Adjustable MS have a theoretic advantage over nonadjustable MS: that is, slings can be easily revised to provide additional urinary stress, in cases of incessant and/or recurrent incontinence, without the requisite for new MS or backup AUS operation. Chung et al. [15] discovered insignificant differences in clinical outcomes and satisfaction rates between adjustable and nonadjustable slings. However, when given the option, more patients selected adjustable over nonadjustable MS [15]. The characteristics and clinical significance of each MS are described below. Fig. 1 shows the representative pictures of various MS.

\section{Adjustable Male Slings Argus sling (Promedon)}

The Argus-T adjustable MS with a transobturator approach appears to be a charming choice because of its material composition, ease of the surgical method, and potential to adjust urethral compression in the postoperative setting [16]. This instrument contains a silicone cushion $2.9-3.5 \mathrm{~cm}$ in width and 3.2$4.5 \mathrm{~cm}$ in length. The pad is linked to 2 silicone columns made of several cone-like parts and 2 silicone rings or washers. The rings are located on the columns to control the tension of the silicone pad on the bulbar urethra. The coned formation of the columns enables to modulate the sling tension by strengthening or loosening the 2 silicone rings [17].

Comprehensive outcomes with this instrument revealed a continence recovery rate of $62 \%-100 \%$ subsequent to a short follow-up $[15,17,18]$, but this variability may have been because of variations in continence interpretation. In the largest analytic study with this instrument, a profitable outcome was achieved (at a median of 22-month follow-up) in $86.2 \%$ of a total of 182 patients with PPI [16]. Regarding degree of incontinence, recent reports showed that continence achievement percentage was poor in patients with severe rather than mild or moderate PPI [16-18]. Regarding complication rates, there are only limited evidences in the publication about adverse events with Argus- $\mathrm{T}$ during surgery; however, after surgery, patients noted problems in $14.3 \%-19.1 \%$ of cases: de novo urgency, hypercontinence, urethral erosion, perineal discomforts, or infections (with a high opportunity of sling elimination in the last 3 conditions) $[16,19]$.

\section{Remeex sling (Neomedic)}

The Remeex system is a modifiable instrument that gives urologists to regulate midurethral pressure during and after surgery, which enable to hypothetically promote the continence achievement possibilities and reduce the complication rate [20]. The mesh is attached by 2 monofilament pulling strings to a su- 
prapubic mechanical regulator, which is embedded subcutaneously over the abdominal rectus fascia, $2 \mathrm{~cm}$ beyond the pubis. Additional rearrangement of the Remeex sling is carried out by an outside controller [21].

Early reports with the Remeex system showed that almost $85 \%$ of patients achieved good midterm results without significant postoperative complications [22]. Nevertheless, rearrangement of the Remeex sling is prevalent, and as far as $90 \%$ of men need minimally 2 adjustments to attain thorough urinary continence. From a study published in 2016, authors evaluated 24 men with PPI and an implanted Remeex sling, the average number of adjustments was $2.41 \pm 1.52$ during long-term follow-up [23]. Recent clinical outcomes from a French study revealed that 9 patients (36\%) were recovered completely, and $9(36 \%)$ were considerably improved, although 7 patients (28\%) showed no major recovery, at the final follow-up date (mean, 31 months) [24].

\section{ATOMS sling (A.M.I. GmbH)}

The ATOMS system consists of an implant with a silicone inflatable cushion and transobturator macroporous, monofilament, polypropylene-mesh arms [25]. The mesh is crossed on either aspect by way of the obturator foramen and fastened to the cushion, hence constructing a 4-point settling architecture that constricts the bulbar urethra ventrally without cutting up the bulbospongiosus (BS) muscle. If needed, the amount of cushion contents can be accommodated after surgery to enhance continence via simple injection of saline in a siliconecapped, preattached port located in the scrotum. Adjustable sling-like-ATOMS is an attractive choice in men with mild-tomoderate incontinence, de novo cognitive/manual deterioration, or unwishful to experience AUS reimplantation [26].

Outcomes, and interpretations of continence, are extremely variable: achievement percentage of continence varied from $92.3 \%$ in a small group of 13 patients [27], to $38.9 \%$ in another study [28]. Seweryn et al. [29] revealed an overall continence accomplishment rate of $84.2 \%$ subsequently to a mean followup of 16.9 months. Moreover, in a retrospective multicenter investigation in 287 patients, the overall continence accomplishment percentage was $90 \%$ and the frequency of cure was $64 \%$ [30]. ATOMS can be a practical substitute for male SUI subsequently to other unsuccessful surgical modalities, such as AUS [31]. The lack of urethral erosion, and minimal infective problems, make ATOMS an excellent alternative for conditions with former treatment failure. The most recent results for ATOMS, after a mean follow-up of 22.1 months, demonstrated that
$30.8 \%$ of patients recovered continence thoroughly, and 59.6\% of patients had diminished urinary losses of $>50 \%$; thus, a total $73.1 \%$ of patients attained social continence [32]. This operation seems to be inventive and has several exclusive aspects: i.e., outpatient adjustment and a single-incision transobturator method. The implant is not contraindicated in men after urethral or previous incontinence operation. Published adverse events contain wound dehiscence, perineal discomfort, urethral injury, and urinary retention $[10,30]$.

\section{Nonadjustable Male Slings AdVance sling (Boston Scientific)}

In 2008, the AdVance male urethral sling appeared as a minimally invasive surgery in treatment of PPI and had favorable early-stage outcomes [33]. The AdVance sling is located by way of a perineal, transobturator access, contributing external mainstay to the urethra under the bladder neck without causing blockage $[34,35]$. Crucial success aspects for the AdVance sling are well-mobilized sphincteric region and acceptable residual sphincter activity [36]. AdVance implantation can also be carried out adequately and harmlessly in patients with SUI subsequently to transurethral resection of the prostate [37].

Most studies assessed success of the AdVance sling utilizing questionnaires about improvements in everyday pad use and quality of life [38-40]. Papachristos et al. [41] estimated the products of approved forms about quality of life and functional outcomes from a total of 72 men underwent the AdVance sling operation. The researchers reported that 37 patients (51\%) were pad free or put on a defense pad, and 18 patients (25\%) had a decline in daily pad use of $\geq 50 \%$, during a median 52-month follow-up. Grabbert et al. [42] identified the effectiveness and safety of AdVance XP in 115 men having PPI. After a follow-up of 48 months, $71.7 \%$ of men were recovered completely and $15.0 \%$ had a better continence condition, whereas $13.3 \%$ were classed as no effect. Postoperative complication rates were not high: de novo urge, a serious grievance in a few men, was also previously reported with an incidence of $0 \%-16 \%$ [43-46]. Typically, significant postoperative adverse events incorporate temporary urinary retention needing short-term reinsertion of urinary catheter, wound dehiscence, perineal discomfort, and inner-thigh sensory paralysis. The possibility of explantation for the AdVance sling is not high [47].

Use of the AdVance sling in salvage continence operation, after recurrence of SUI with an unsuccessful transobturator sling, revealed that $56 \%$ of men achieved an overall success; in total, 
complete continence rate was $39 \%$ subsequently to 17.5 months of follow-up [48]. Men with SUI recurrence secondary to cuffcompression atrophy can be recovered from incontinent by applying an MS rather than by revision with an AUS instrument [49]. The benefits of utilizing AdVance as salvage in AUS men with recurrent SUI are a reduced possibility of infections after surgery due to nonviolation of an AUS pseudo-capsule, and the likelihood that the patient will not have to depend solely on an AUS to maintain continence.

\section{Virtue sling (Coloplast)}

The Virtue Quadratic MS was devised to offer both urethral support and prepubic compression, thus causing it an applicable choice for a broader scope of patients with PPI ranging from mild to severe [50]. This device comprises a 4-arm, polypropylene-mesh sling with 2 transobturator arms and 2 prepubic arms. A further advantage of this instrument is the competence to reorganize and constrict the sling if the mesh fails after surgery.

The initial publication about use of the Virtue sling focused primarily on improvements in retrograde leak point pressure (RLPP) [51]. These researchers showed that sling placement led to an average $106 \%$ increase in RLPP from baseline (i.e., from 33.4 to $68.8 \mathrm{~cm} \mathrm{H}_{2} \mathrm{O}$ ). One published, multinational clinical trial showed a $50 \%$ reduction in pad use in $79 \%$ of men; in $46 \%$ of these patients, symptoms were cured after 12 months [50]. Few publications have detailed the long-term effectiveness and safety of Virtue sling placement. Possible complications incorporate wound dehiscence, perineal discomfort, and urinary retention.

\section{I-STOP TOMS (CL Medical)}

The I-STOP TOMS is a monofilament, polypropylene (macropores $>75 \mu \mathrm{m}$ ), nonextensible, four-arm, large sling, like AdVance [52]. However, the BS muscle is left unharmed and the central tendon is not incised. The helical trocars are passed in an outside-in fashion. Tensioning is performed sufficiently to indent the BS muscle.

A multi-institutional trial evaluating 12-month outcomes after I-STOP TOMS placement in 122 patients was reported in 2012 [53]. Overall, 87.0\% of men noted better continence situation, with $59.4 \%$ absolutely dry at 12 months; $13 \%$ revealed no enhancement, yet an absence of deterioration. The quality of life has been greatly improved at initail follow-up, and symptomatic improvements were continued during the entire followup period. Patients were very pleased with the procedure and with their new status of health. Yiou et al. [54] published data from a 40-patient series about use of a TOMS sling with 2-year follow-up; the series included men who had experienced RT prior to sling placement. The investigators showed that almost half of men were not wearing any pads at the 2-year follow-up time. Nonetheless, outcomes also suggested that some incontinence disorder may happen after the first year, and questions about the long-term durability of I-STOP TOMS were raised. In a recent, retrospective, multi-institutional study, only $15 \%$ of patients were dry, and $22 \%$ were socially continent, 5 years after device implantation [55].

\section{ARTIFICIAL URINARY SPHINCTERS DEVICES}

While synthetic MS have an adequate position in the management of mild-to-moderate PPI, they do not have efficacy in moderate-to-severe PPI or in high-risk groups, including patients with a history of RT, use of urethral bulking agents, complications of sling surgery, transurethral prostate surgery, or urethral fibrosis [56]. The urinary cuff supplies encircling closure to the urethral lumen, bring about complete mucosal coaptation. Further, fluid transfer from an extra reservoir factor can possibly increase pressure in the blocking urethral cuff, thereby simulating a more physiologic sphincter motion. We represent the AUS devices introduced in this manuscript as Fig. 2.

\section{AMS 800 (American Medical Systems, Minnetonka, MN, USA)}

The prototype AUS instrument was developed in 1973 and was then adjusted a several times, finally, the present design was established in 1987 [57,58]. Nowadays, AMS 800 is the main treatment modality for constant moderate and severe PPI and remains the treatment of choice for male SUI. Moreover, AMS 800 implantation in selected groups of women with severe or recurrent SUI or neurogenic dysfunction has been performed during the past 3 decades in a few centers worldwide [59]. This instrument contains an inflatable occluding cuff, a pressure regulating balloon (PRB), and a control pump.

Most patients who experience AUS implantation for PPI obtain satisfying results (0-1 pad per day) [60-67]. The frequency of infection ranges from $0.5 \%-7.0 \%$, cuff erosion rates from $3.8 \%-10.0 \%$, and urethral atrophy rates from $9.6 \%-11.4 \%$ $[64,65,68]$. Current general agreement among high-volume surgeons revealed that AMS 800 implantation is left a highly specialized operation with particular trials. Careful patient selection and adequate surgical management are left great for ex- 

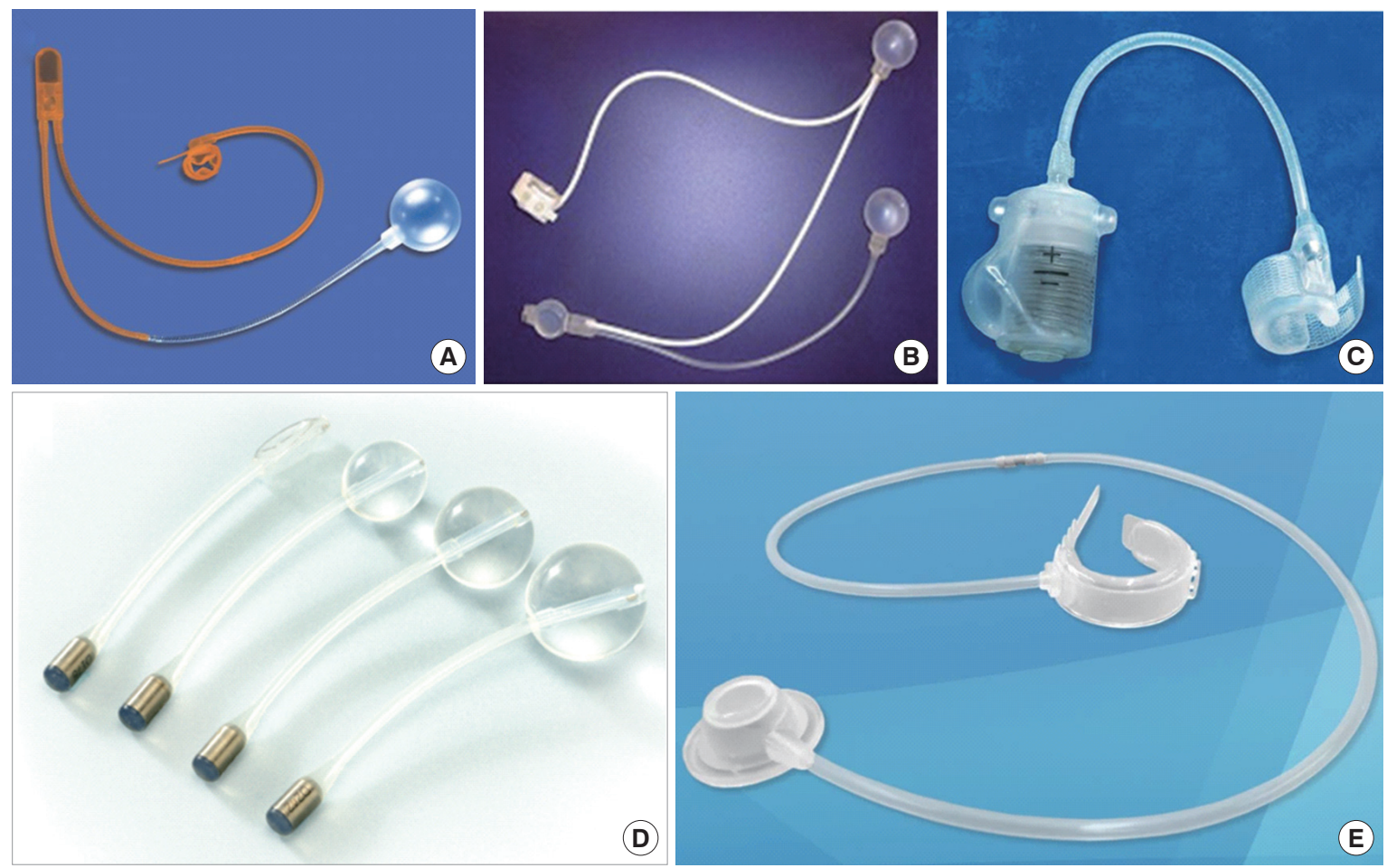

Fig. 2. Artificial urinary sphincter (AUS) devices. (A) AMS 800, (B) FlowSecure sphincter, (C) Zephyr ZSI 375, (D) Pro-ACT device, (E) Periurethral constrictor device.

cellent surgical results [69]. In order to reduce urethral atrophy and increase the rate of continence acquisition, a dual (tandem) cuff system was introduced, however, this system was associated with higher adverse event rates [70].

Revision surgeries contain substitute of the defective unit, cuff replacement, repositioning or downsizing due to urethral atrophy, or placement of a second tandem cuff or transcorporal cuff [69,71-73]. Urethral atrophy is an adverse event of AUS that is confusing to predict. It commonly appears as an increase in number of incontinence episode and in pad usage. If other matters of SUI have been excluded, diagnosis is established. When surgeons perform a revision operation, the AUS instrument will still be working. To reduce urethral atrophy, Serag et al. [74] leave the BS muscle intact and use a larger size cuff to ensure that the cuff is never too tight.

\section{FlowSecure device (Barloworld Scientific Limited, Stone, Staffordshire, UK)}

The FlowSecure AUS instrument was originally constructed by Craggs and colleagues [75]. This modernized AUS instrument attempted to focus on 2 significant shortcomings of the AMS 800 , specifically incompetence of the PRB to accommodate to alterations in intra-abdominal and bladder pressures; and the requirement for revision operation after cuff atrophy [57]. This unitary silicone instrument is prefilled with $30 \mathrm{~mL}$ of normal saline and consists of 4 components linked by silicone cylinder: a PRB, a stress release balloon, a circular occluding urethral cuff, and a control pump [75]. An early concern with the FlowSecure design was the possibility of cuff rupture during giving pressure, but this concern seems to be fixed with a new control pump with a resistance valve [76].

At present, there are very few FlowSecur instruments implanted, thus there is a paucity of published long-term follow-up data. However, a preliminary data about results with the FlowSecure instrument was promising: at least 12 months of follow-up, more than 10 times volume reduction in average daily leakage was observed (from 770.6 to $55.1 \mathrm{~mL}$ ), and it was clear that the Continence Index improved overall from 54\% to 97\% [76].

\section{Zephyr ZSI 375 (Mayor Group, Villeurbanne, France)}

Zephyr ZSI 375 is another all-in-one silicone-elastomeric urinary continence instrument [77]. Constraint can be accomplished to prevent urine leakage. The device has no abdominal reservoir, thereby reducing surgery time and evading abdomi- 
nal incision and dissection of scarred retroperitoneum [78,79].

Theoretic benefits of the Zephyr instrument over the AMS 800 instrument are as followings: device pressure can be adjusted by infusing or abolishing fluid from the compensation pocket; and without the third component, which must be placed in the retropubic area, the possibility of bladder damage and instrument movement is reduced [78]. Recently published data revealed that any complications did not occur during surgery, however, ZSI 375 instrument implantation was related to a $61.5 \%$ overall explanation rate [80]. Ostrowski et al. [77] reported results from 4-year follow-up of ZSI 375 . In their study, social continence ( $0-1 \mathrm{pad} /$ day) was achieved in 29 of 50 patients (58\%), and an improvement ( $\geq 50 \%$ fewer pads/day) was achieved in 15 of 50 patients (30\%). Failure occurred in 6 of 50 patients $(12 \%)$ [77]. Widely known adverse events were instrument errors, device infection, constant discomfort, and urethral erosion.

\section{Adjustable Continence Therapy (Pro-ACT) (Uromedica Inc., Plymouth, MN, USA)}

The Pro-ACT device, consisting of 2 silicone balloons at the proximal end and a titanium port at the distal end, was initially produced for the management of SUI in female patients [81,82]. The 2 balloons are located transperineally to the urethral junction level bilaterally under fluoroscopy or transrectal ultrasound navigation. Recent researches have demonstrated the use of a navigation guidance system to confine an introduction mandrel mounting a tracked target; there was no considerable difference between rigid cystoscopy and retrovision in balanced location of puncture sites for the silicone balloons [83]. Expected benefits of the Pro-ACT instrument contain: technical ease of implantation, relatively low morbidity, cheap price, a lack of circumferential urethral compression, and the capacity to modulate the amount of urethral compression.

Recent article revealed that satisfied management with ProACT was related to a significant increase in maximum urethral closure pressure (from a median of 58.0 to $79.0 \mathrm{~cm} \mathrm{H}_{2} \mathrm{O}$ ) and that increased static urethral pressure devoted to function of the instrument [84]. Previous publications about Pro-ACT revealed a meaningful enhancement in patient dry rates after an average of 3 balloon volume modifications [81]. The reported initial success rate of this treatment was high (67\%), but more than a third of patients were not satisfied with the outcome of the surgery. Similar to MS, the success rate was not favorable in men who underwent RT and had severe UI. Previous researches demonstrated relatively high adverse event rates (i.e., urethral or bladder rupture, instrumental malfunction, migration, infection, and erosion) [85], but these rates decreased with surgical experience [86]. Long-term outcomes with this instrument, and possible bladder alterations due to voiding against persistent outlet resistance, are unexplained. Thus, the possible disadvantages of this instrument should be compared with the probable benefits of an adjustable continence system. Nevertheless, it seems that the Pro-ACT instrument may offer several added advantages regarding improved continence in cases of constant incontinence subsequently to MS implantation [87].

\section{Periurethral Constrictor (Silimed, Rio de Janeiro, Brazil)}

In 1996, de O Vilar et al. initially demonstrated the usefulness and safety of implantation of a new type of periurethral constrictor in children with neuropathic sphincteric incompetence $[88,89]$. This instrument includes a constrictor cuff connected by a tube to a hydraulically stimulated self-sealing valve. The cuff consists of a silicone membrane, shaped like an open and inflatable ring, with a polyurethane foam coat on the inner surface and a polyester tissue reinforcement band on the outer surface. The external band includes 2 pairs of buttons and 4 pairs of holes along its length to approve for instrument rearrangement around the bladder neck or bulbar urethra. The 2 sections of silicone tubes (200 and $500 \mathrm{~mm}$ long) are co-operated by a plastic connector linking the valve to the constrictor cuff and provide for modification of the interval between valve and cuff.

The initial research revealed favorable results for PPI men: $73.3 \%$ of men had functional instruments and were socially dry at a mean follow-up of 42.1 months [90]. Yet, periurethral constrictor suffered from high adverse event rates: i.e., the need for added fluid in the port to increase occlusive static pressure of the cuff (7 patients), urethral erosion (4 patients), instrument infection (3 patients), and instrument failure due to leakage of saline solution (4 patients). Similar outcomes were represented by Introini et al. [91] in a recent, retrospective series of 66 patients with severe UIMost patients (79\%) were dry at follow-up, 15\% improved, and $6 \%$ failed. Intriguingly, the frequency of urethral erosions was negligible (6\%), most likely due to the short followup of 18 months. Favro et al. [92] described long-term results associated with periurethral constrictor insertion for PPI. In their study, 47 of the postoperative complications (78.3\%) occurred in 30 patients. Twenty-three patients (38.3\%) progressed urethral erosion at a median follow-up of 27.5 months, and 1 patient (1.9\%) went through rectourethral fistula at 2 months.

These findings were affirmed by Lima et al. [93], who recent- 
ly evaluated a retrospective series of $56 \mathrm{men}$. They represented that $41 \%$ of men needed dislodgment of the instrument after an average follow-up of 82.2 months. The mean interval between operation and device extraction was 22.6 months and the most common adverse event was urethral erosion (26.8\% of cases). Contrary to the AMS 800 instrument, the periurethral constrictor is comparably low-priced and manipulation of a pump is not required for voiding. However, patients must void against persistent resistance made by the instrument, and long-term effects of this mechanical compression on the urethra and upper urinary tract are unexplained. Although preliminary results with the periurethral constrictor are promising, larger cohort and expanded periods of follow-up are needed to represent the long-term efficacy and safety of this instrument.

\section{FUTURE PERSPECTIVES}

New developmental continence instruments require to be revolutionary in shape, closely replicate an intact human sphincter, and respond appropriately to diverse external and internal stimulation. Emerging innovative treatment modalities, including nanotechnology driven devices and stem cell treatment, are very promising, however, are not yet universally commercialized or are still lack of proven long-term clinical results [94,95]. Until the development of an advanced engineered urinary instrument, and/or further advances in stem cell treatment or tissue engineering, important challenges remain in the investigation for an optimal urinary continence treatment. AUS instruments are relatively rigid and likely to lead to atrophy and erosion in the future. Accordingly, it is deeply helpful to have a substitute and more advanced innovative urinary continence instruments that imitate natural sphincter motion.

\section{CONCLUSIONS}

PPI is not an infrequent event. It negatively disturbs patients' quality of life and is related to considerable economic pressure. Pelvic floor muscle exercise is advocated for the initial management of SUI, while anticholinergic medicine is applied for urgency or urge incontinence. For several decades, AUS was the treatment of choice in consistent PPI patients. Nowadays, MS are an alternative for men with mild-to-moderate PPI.

The appearance of synthetic slings in the present medical field provides less invasive operation and allows for immediate continence and the capability to void without manual control.
MS are a charming substitute for patients who want to avoid mechanical manipulation during urinary voiding, and midterm outcome support favorable safety and effectiveness rates in men with mild-to-moderate SUI. Despite a plethora of new literature during the past decade, there is no consensus about which sling modality is the most effective. Heterogeneity in patient selection, poorly defined baseline incontinence, variability in the definition of success, and relatively short follow-up have limited generalizable conclusions and made it difficult to compare individual slings. Therefore, proper preoperative selection is paramount. The other strength of MS is, as previous researches demonstrate, that these devices have lower complication rates than AUS [96]. Nevertheless, the AMS 800 instrument is regarded as the treatment of choice in moderate-to-severe PPI patients and has the longest effectiveness and safety evidences. Decades of developments in mechanical shape, progressive technologies, and messages learned from clinical practices and experiences have affected a novel generation of AUS instruments. Other continence instruments in clinical fields have shown encouraging results during short- to mid-term followup but long-term efficacy and safety data are needed.

When we are planning the male PPI surgery, careful preoperative work-up should be performed and surgical method should be chosen according to the severity of the disease. Male sling is preferred in mild and moderate symptomatic patients with normal detrusor pressure and it is recommended to select traditional AUS device in those with severe symptoms. It is expected that effective devices without adverse events will be developed with technical advances in near future.

\section{AUTHOR CONTRIBUTION STATEMENT}

- Full access to all the data in the study and takes responsibility for the integrity of the data and the accuracy of the data analysis: $E S Y$

- Study concept and design: ESY

- Acquisition of data: YSH

- Analysis and interpretation of data: ESY, YSH

- Drafting of the manuscript: YSH

- Critical revision of the manuscript for important intellectual content: ESY

- Statistical analysis: $Y S H$

- Obtained funding: $Y S H$

- Administrative, technical, or material support: ESY, YSH

-Study supervision: ESY 


\section{REFERENCES}

1. Abrams P, Andersson KE, Birder L, Brubaker L, Cardozo L, Chapple $\mathrm{C}$, et al. Fourth International Consultation on Incontinence Recommendations of the International Scientific Committee: Evaluation and treatment of urinary incontinence, pelvic organ prolapse, and fecal incontinence. Neurourol Urodyn 2010;29:213-40.

2. Johansson E, Steineck G, Holmberg L, Johansson JE, Nyberg T, Ruutu $\mathrm{M}$, et al. Long-term quality-of-life outcomes after radical prostatectomy or watchful waiting: the Scandinavian Prostate Cancer Group-4 randomised trial. Lancet Oncol 2011;12:891-9.

3. Hefermehl L, Bossert K, Ramakrishnan VM, Seifert B, Lehmann K. A Prospective Analysis of the Effects of Nerve-Sparing Radical Prostatectomy on Urinary Continence Based on Expanded Prostate Cancer Index Composite and International Index of Erectile Function Scoring Systems. Int Neurourol J 2018;22:123-32.

4. Cornu JN, Peyrat L, Haab F. Update in management of male urinary incontinence: injectables, balloons, minimally invasive approaches. Curr Opin Urol 2013;23:536-9.

5. Ventimiglia E, Folkvaljon Y, Carlsson S, Bratt O, Montorsi F, Volz D, et al. Nationwide, population-based study of post radical prostatectomy urinary incontinence correction surgery. J Surg Oncol 2018; 117:321-7.

6. Thüroff JW, Abrams P, Andersson KE, Artibani W, Chapple CR, Drake MJ, et al. EAU guidelines on urinary incontinence. Eur Urol 2011;59:387-400.

7. Nam RK, Herschorn S, Loblaw DA, Liu Y, Klotz LH, Carr LK, et al. Population based study of long-term rates of surgery for urinary incontinence after radical prostatectomy for prostate cancer. J Urol 2012;188:502-6.

8. Kim PH, Pinheiro LC, Atoria CL, Eastham JA, Sandhu JS, Elkin EB. Trends in the use of incontinence procedures after radical prostatectomy: a population based analysis. J Urol 2013;189:602-8.

9. Andreasson A, Fall M, Persson E, Stranne J, Peeker R. High revision rate following artificial urethral sphincter implantation. Scand J Urol 2014;48:544-8.

10. Chung E. Contemporary surgical devices for male stress urinary incontinence: a review of technological advances in current continence surgery. Transl Androl Urol 2017;6(Suppl 2):S112-21.

11. Van Bruwaene S, De Ridder D, Van der Aa F. The use of sling vs sphincter in post-prostatectomy urinary incontinence. BJU Int 2015;116:330-42.

12. Ko KJ, Kim SJ, Cho ST. Sling surgery for male urinary incontinence including post prostatectomy incontinence: a challenge to the urologist. Int Neurourol J 2019;23:185-94.
13. Sandhu JS, Breyer B, Comiter C, Eastham JA, Gomez C, Kirages DJ, et al. Incontinence after prostate treatment: AUA/SUFU Guideline. J Urol 2019;202:369-78.

14. Kumar A, Litt ER, Ballert KN, Nitti VW. Artificial urinary sphincter versus male sling for post-prostatectomy incontinence--what do patients choose? J Urol 2009;181:1231-5.

15. Chung E, Smith P, Malone G, Cartmill R. Adjustable versus nonadjustable male sling for post-prostatectomy urinary incontinence: a prospective clinical trial comparing patient choice, clinical outcomes and satisfaction rate with a minimum follow up of 24 months. Neurourol Urodyn 2016;35:482-6.

16. Siracusano S, Visalli F, Favro M, Tallarigo C, Saccomanni M, Kugler A, et al. Argus-T sling in 182 male patients: short-term results of a multicenter study. Urology 2017;110:177-83.

17. Romano SV, Huebner W, Rocha FT, Vaz FP, Muller V, Nakamura F. A transobturator adjustable system for male incontinence: 30-month follow-up of a multicenter study. Int Braz J Urol 2014;40: 781-9.

18. Bauer RM, Rutkowski M, Kretschmer A, Casuscelli J, Stief CG, Huebner W. Efficacy and complications of the adjustable sling system ArgusT for male incontinence: results of a prospective 2-center study. Urology 2015;85:316-20.

19. Hübner WA, Gallistl H, Rutkowski M, Huber ER. Adjustable bulbourethral male sling: experience after 101 cases of moderate-tosevere male stress urinary incontinence. BJU Int 2011;107:777-82.

20. Chung JW, Yoo ES. Efficacy and safety of a readjustable midurethral sling (Remeex system) for stress urinary incontinence with female voiding dysfunction. Investig Clin Urol 2017;58:127-33.

21. Sousa-Escandón A, Rodríguez Gómez JI, Uribarri González C, Marqués-Queimadelos A. Externally readjustable sling for treatment of male stress urinary incontinence: points of technique and preliminary results. J Endourol 2004;18:113-8.

22. Sousa-Escandón A, Cabrera J, Mantovani F, Moretti M, Ioanidis E, Kondelidis N, et al. Adjustable suburethral sling (male remeex system) in the treatment of male stress urinary incontinence: a multicentric European study. Eur Urol 2007;52:1473-9.

23. Navalón-Monllor V, Ordoño-Domínguez F, Pallás-Costa Y, VilarCastro LA, Monllor-Peidro ME, Juan-Escudero J, et al. Long-term follow-up for the treatment of male urinary incontinence with the Remeex system. Actas Urol Esp 2016;40:585-91.

24. Leizour B, Chevrot A, Wagner L, Droupy S, Costa P. Adjustable retropubic suburethral sling Remeex in the treatment of male stress urinary incontinence: one-year results. Prog Urol 2017;27: 238-43.

25. Bauer W, Karik M, Schramek P. The self-anchoring transobturator 
male sling to treat stress urinary incontinence in men: a new sling, a surgical approach and anatomical findings in a cadaveric study. BJU Int 2005;95:1364-6.

26. Kretschmer A, Hübner W, Sandhu JS, Bauer RM. Evaluation and management of postprostatectomy incontinence: a systematic review of current literature. Eur Urol Focus 2016;2:245-59.

27. González SP, Cansino JR, Portilla MA, Rodriguez SC, Hidalgo L, De la Peña J. First experience with the ATOMS( $\left.{ }^{\circledR}\right)$ implant, a new treatment option for male urinary incontinence. Cent European J Urol 2014;67:387-91.

28. Krause J, Tietze S, Behrendt W, Nast J, Hamza A. Reconstructive surgery for male stress urinary incontinence: experiences using the ATOMS $\left({ }^{\circledR}\right)$ system at a single center. GMS Interdiscip Plast Reconstr Surg DGPW 2014;3:Doc15.

29. Seweryn J, Bauer W, Ponholzer A, Schramek P. Initial experience and results with a new adjustable transobturator male system for the treatment of stress urinary incontinence. J Urol 2012;187:95661.

30. Friedl A, Mühlstädt S, Zachoval R, Giammò A, Kivaranovic D, Rom M, et al. Long-term outcome of the adjustable transobturator male system (ATOMS): results of a European multicentre study. BJU Int 2017;119:785-92.

31. Angulo JC, Esquinas C, Arance I, Rodríguez A, Pereira J, Rabassa $M$, et al. Adjustable transobturator male system after failed surgical devices for male stress urinary incontinence: a feasibility study. Urol Int 2018;101:106-13.

32. Giammò A, Ammirati E, Tullio A, Bodo G, Manassero A, Gontero $\mathrm{P}$, et al. Implant of ATOMS ${ }^{\circledR}$ system for the treatment of postoperative male stress urinary incontinence: results of a single centre. Int Braz J Urol 2019;45:127-36.

33. Bauer RM, Mayer ME, Gratzke C, Soljanik I, Buchner A, Bastian PJ, et al. Prospective evaluation of the functional sling suspension for male postprostatectomy stress urinary incontinence: results after 1 year. Eur Urol 2009;56:928-33.

34. Rehder P, Gozzi C. Transobturator sling suspension for male urinary incontinence including post-radical prostatectomy. Eur Urol 2007;52:860-6.

35. Davies TO, Bepple JL, McCammon KA. Urodynamic changes and initial results of the AdVance male sling. Urology 2009;74:354-7.

36. Rehder P, Freiin von Gleissenthall G, Pichler R, Glodny B. The treatment of postprostatectomy incontinence with the retroluminal transobturator repositioning sling (Advance): lessons learnt from accumulative experience. Arch Esp Urol 2009;62:860-70.

37. Kretschmer A, Buchner A, Leitl B, Grabbert M, Sommer A, Khoder $\mathrm{W}$, et al. Long-term outcome of the retrourethral transobturator male sling after transurethral resection of the prostate. Int Neurourol J 2016;20:335-41.

38. Cornu JN, Sèbe P, Ciofu C, Peyrat L, Cussenot O, Haab F. Midterm evaluation of the transobturator male sling for post-prostatectomy incontinence: focus on prognostic factors. BJU Int 2011;108: 236-40.

39. Rehder P, Haab F, Cornu JN, Gozzi C, Bauer RM. Treatment of postprostatectomy male urinary incontinence with the transobturator retroluminal repositioning sling suspension: 3-year followup. Eur Urol 2012;62:140-5.

40. Bauer RM, Soljanik I, Füllhase C, Karl A, Becker A, Stief CG, et al. Mid-term results for the retroluminar transobturator sling suspension for stress urinary incontinence after prostatectomy. BJU Int 2011;108:94-8.

41. Papachristos A, Mann S, Talbot K, Moon D. AdVance male urethral sling: medium-term results in an Australian cohort. ANZ J Surg 2018;88:E178-82.

42. Grabbert M, Mumm JN, Klehr B, Kretschmer A, Gebhartl P, Gozzi $\mathrm{C}$, et al. Extended follow-up of the AdVance XP male sling in the treatment of male urinary stress incontinence after 48 months: Results of a prospective and multicenter study. Neurourol Urodyn 2019;38:1973-8.

43. Kretschmer A, Grabbert M, Sommer A, Stief CG, Bauer RM. Midterm outcomes after AdVanceXP male sling implantation. BJU Int 2016;118:458-63.

44. Bauer RM, Gozzi C, Klehr B, Kretschmer A, Grabbert M, Rehder P, et al. AdVanceXP male sling: 2-year results of a multicentre study. World J Urol 2016;34:1025-30.

45. Kowalik CG, DeLong JM, Mourtzinos AP. The advance transobturator male sling for post-prostatectomy incontinence: subjective and objective outcomes with 3 years follow up. Neurourol Urodyn 2015;34:251-4.

46. Collado A, Domínguez-Escrig J, Ortiz Rodríguez IM, RamirezBackhaus M, Rodríguez Torreblanca C, Rubio-Briones J. Functional follow-up after Advance ${ }^{\circledast}$ and Advance $\mathrm{XP}^{\circledR}$ male sling surgery: assessment of predictive factors. World J Urol 2019;37:195-200.

47. Bauer RM, Mayer ME, May F, Gratzke C, Buchner A, Soljanik I, et al. Complications of the AdVance transobturator male sling in the treatment of male stress urinary incontinence. Urology 2010;75: 1494-8.

48. Martinez EJ, Zuckerman JM, Henderson K, Edwards B, McCammon K. Evaluation of salvage male transobturator sling placement following recurrent stress urinary incontinence after failed transobturator sling. Urology 2015;85:478-82.

49. Christine B, Knoll LD. Treatment of recurrent urinary inconti- 
nence after artificial urinary sphincter placement using the AdVance male sling. Urology 2010;76:1321-4.

50. Comiter CV, Rhee EY, Tu LM, Herschorn S, Nitti VW. The virtue sling--a new quadratic sling for postprostatectomy incontinence-results of a multinational clinical trial. Urology 2014;84:433-8.

51. Comiter CV, Nitti V, Elliot C, Rhee E. A new quadratic sling for male stress incontinence: retrograde leak point pressure as a measure of urethral resistance. J Urol 2012;187:563-8.

52. Grise P, Geraud M, Geraud M, Lienhart J, Le Portz B, Bubenheim $\mathrm{M}$, et al. Transobturator male sling TOMS for the treatment of stress post-prostatectomy incontinence, initial experience and results with one year's experience. Int Braz J Urol 2009;35:706-13.

53. Grise P, Vautherin R, Njinou-Ngninkeu B, Bochereau G, Lienhart J, Saussine C, et al. I-STOP TOMS transobturator male sling, a minimally invasive treatment for post-prostatectomy incontinence: continence improvement and tolerability. Urology 2012;79:458-63.

54. Yiou R, Bütow Z, Parisot J, Lingombet O, Augustin D, de la Taille A, et al. Update on 2-year outcomes of the TOMS ${ }^{\mathrm{TM}}$ transobturator male sling for the treatment of male stress urinary incontinence. Neurourol Urodyn 2016;35:44-7.

55. Malval B, Rebibo JD, Baron M, Nouhaud FX, Pfister C, Cornu JN, et al. Long-term outcomes of I-Stop TOMS ${ }^{\mathrm{TM}}$ male sling implantation for post-prostatectomy incontinence management. Prog Urol 2017;27:1084-90.

56. Doudt AD, Zuckerman JM. Male Slings for Post-prostatectomy Incontinence. Rev Urol 2018;20:158-69.

57. Chung E, Ranaweera M, Cartmill R. Newer and novel artificial urinary sphincters (AUS): the development of alternatives to the current AUS device. BJU Int 2012;110 Suppl 4:5-11.

58. Montague DK. Artificial urinary sphincter: long-term results and patient satisfaction. Adv Urol 2012;2012:835290.

59. Reus CR, Phé V, Dechartres A, Grilo NR, Chartier-Kastler EJ, Mozer PC. Performance and safety of the artificial urinary sphincter (AMS 800) for non-neurogenic women with urinary incontinence secondary to intrinsic sphincter deficiency: a systematic review. Eur Urol Focus 2018 Oct 30. pii: S2405-4569(18)30302-X.

60. Litwiller SE, Kim KB, Fone PD, White RW, Stone AR. Post-prostatectomy incontinence and the artificial urinary sphincter: a longterm study of patient satisfaction and criteria for success. J Urol 1996;156:1975-80.

61. Haab F, Trockman BA, Zimmern PE, Leach GE. Quality of life and continence assessment of the artificial urinary sphincter in men with minimum 3.5 years of followup. J Urol 1997;158:435-9.

62. Montague DK, Angermeier KW, Paolone DR. Long-term continence and patient satisfaction after artificial sphincter implantation for urinary incontinence after prostatectomy. J Urol 2001;166:5479.

63. O'Connor RC, Nanigian DK, Patel BN, Guralnick ML, Ellision LM, Stone AR. Artificial urinary sphincter placement in elderly men. Urology 2007;69:126-8.

64. Raj GV, Peterson AC, Toh KL, Webster GD. Outcomes following revisions and secondary implantation of the artificial urinary sphincter. J Urol 2005;173:1242-5.

65. Kim SP, Sarmast Z, Daignault S, Faerber GJ, McGuire EJ, Latini JM. Long-term durability and functional outcomes among patients with artificial urinary sphincters: a 10-year retrospective review from the University of Michigan. J Urol 2008;179:1912-6.

66. Gousse AE, Madjar S, Lambert MM, Fishman IJ. Artificial urinary sphincter for post-radical prostatectomy urinary incontinence: long-term subjective results. J Urol 2001;166:1755-8.

67. Trigo Rocha F, Gomes CM, Mitre AI, Arap S, Srougi M. A prospective study evaluating the efficacy of the artificial sphincter AMS 800 for the treatment of postradical prostatectomy urinary incontinence and the correlation between preoperative urodynamic and surgical outcomes. Urology 2008;71:85-9.

68. Lai HH, Hsu EI, Teh BS, Butler EB, Boone TB. 13 years of experience with artificial urinary sphincter implantation at Baylor College of Medicine. J Urol 2007;177:1021-5.

69. Biardeau X, Aharony S; AUS Consensus Group, Campeau L, Cor$\cos$ J. Artificial urinary sphincter: report of the 2015 consensus conference. Neurourol Urodyn 2016;35 Suppl 2:S8-24.

70. O'Connor RC, Lyon MB, Guralnick ML, Bales GT. Long-term follow-up of single versus double cuff artificial urinary sphincter insertion for the treatment of severe postprostatectomy stress urinary incontinence. Urology 2008;71:90-3.

71. Chung E, Cartmill R. Diagnostic challenges in the evaluation of persistent or recurrent urinary incontinence after artificial urinary sphincter (AUS) implantation in patients after prostatectomy. BJU Int 2013;112 Suppl 2:32-5.

72. Queissert F, Huesch T, Kretschmer A, Anding R, Kurosch M, Kirschner-Hermanns R, et al. Artificial urinary sphincter cuff size predicts outcome in male patients treated for stress incontinence:

results of a large central european multicenter cohort study. Int Neurourol J 2019;23:219-25.

73. Guralnick ML, Miller E, Toh KL, Webster GD. Transcorporal artificial urinary sphincter cuff placement in cases requiring revision for erosion and urethral atrophy. J Urol 2002;167:2075-8.

74. Serag H, Bang S, Almallah YZ. Artificial urinary sphincters for treating postprostatectomy incontinence: a contemporary experience from the UK. Res Rep Urol 2018;10:63-8. 
75. Knight SL, Susser J, Greenwell T, Mundy AR, Craggs MD. A new artificial urinary sphincter with conditional occlusion for stress urinary incontinence: preliminary clinical results. Eur Urol 2006; 50:574-80.

76. García-Montes F. FlowSecure artificial urinary sphincter for the treatment of stress urinary incontinence after radical prostatectomy. Arch Esp Urol 2009;62:845-50.

77. Ostrowski I, Ciechan J, Sledz E, Dys W, Golabek T, Chłosta PL. Four-year follow-up on a Zephyr Surgical Implants 375 artificial urinary sphincter for male urinary incontinence from one urological centre in Poland. Cent European J Urol 2018;71:320-5.

78. Staerman F, G-Llorens C, Leon P, Leclerc Y. ZSI 375 artificial urinary sphincter for male urinary incontinence: a preliminary study. BJU Int 2013;111(4 Pt B):E202-6.

79. Ostrowski I, Blewniewski M, Neugart F, von Heyden B, Selvaggio O, Iori F, et al. Multicentre experience with ZSI 375 artificial urinary sphincter for the treatment of stress urinary incontinence in men. Urologia 2017;84:148-52.

80. Kretschmer A, Hüsch T, Thomsen F, Kronlachner D, Pottek T, Obaje A, et al. Efficacy and safety of the ZSI375 artificial urinary sphincter for male stress urinary incontinence: lessons learned. World J Urol 2016;34:1457-63.

81. Hübner WA, Schlarp OM. Treatment of incontinence after prostatectomy using a new minimally invasive device: adjustable continence therapy. BJU Int 2005;96:587-94.

82. Gregori A, Romanò AL, Scieri F, Pietrantuono F, Incarbone GP, Salvaggio A, et al. Transrectal ultrasound-guided implantation of Adjustable Continence Therapy (ProACT): surgical technique and clinical results after a mean follow-up of 2 years. Eur Urol 2010;57: 430-6.

83. Chevrot A, Jaffard A, Medici M, Costa P, Wagner L, MoreauGaudry A, Rigid cystoscopy versus retrovision for adjustable periurethral balloons guidance: comparison of precision thanks to a surgical navigation system. Prog Urol 2016;26:566-72.

84. Reuvers SH, Groen J, Scheepe JR, Blok BF. Maximum urethral closure pressure increases after successful adjustable continence therapy (ProACT) for stress urinary incontinence after radical prostatectomy. Urology 2016;94:188-92.

85. Lebret T, Cour F, Benchetrit J, Grise P, Bernstein J, Delaporte V, et al. Treatment of postprostatectomy stress urinary incontinence using a minimally invasive adjustable continence balloon device,
ProACT: results of a preliminary, multicenter, pilot study. Urology 2008;71:256-60.

86. Gilling PJ, Bell DF, Wilson LC, Westenberg AM, Reuther R, Fraundorfer MR. An adjustable continence therapy device for treating incontinence after prostatectomy: a minimum 2-year follow-up. BJU Int 2008;102:1426-30.

87. Yiou R, Butow Z, Baron T, Salomon L, Audureau E. Adjustable continence therapy (ProACT ${ }^{\mathrm{Tm}}$ ) after male sling failure for patients with post-radical prostatectomy urinary incontinence: a prospective study with one-year follow-up. World J Urol 2015;33:1331-6.

88. Lima SV, Araújo LA, Vilar FO, Kummer CL, Lima EC. Combined use of enterocystoplasty and a new type of artificial sphincter in the treatment of urinary incontinence. J Urol 1996;156(2 Pt 2):622-4.

89. de O Vilar F, Araújo LA, Lima SV. Periurethral constrictor in pediatric urology: long-term followup. J Urol 2004;171:2626-8.

90. Schiavini JL, Damião R, de Resende Júnior JA, Dornas MC, Cruz Lima da Costa DS, Barros CB. Treatment of post-prostate surgery urinary incontinence with the periurethral constrictor: a retrospective analysis. Urology 2010;75:1488-92.

91. Introini C, Naselli A, Zaninetta G, Timossi L, Guaglianone S, Simone $\mathrm{G}$, et al. Safety and efficacy of periurethral constrictor implantation for the treatment of post-radical prostatectomy incontinence. Urology 2012;79:1175-8.

92. Favro M, Billia M, Volpe A, Zacchero M, Terrone C. Long-term outcomes of the implant of a periurethral constrictor for stress urinary incontinence following radical prostatectomy. Urol Int 2016;97:26-31.

93. Lima RS, Barros EG, Souza CA, de O Vilar F, Lima SV. Periurethral constrictor: late results of the treatment of post prostatectomy urinary incontinence. Int Braz J Urol 2011;37:483-7.

94. Müller B, Deyhle H, Mushkolaj S, Wieland M. The challenges in artificial muscle research to treat incontinence. Swiss Med Wkly 2009;139:591-5.

95. Pelrine R, Kornbluh R, Pei Q, Joseph J. High-speed electrically actuated elastomers with strain greater than $100 \%$. Science 2000;287: 836-9.

96. Alwaal A, Harris CR, Awad MA, Allen IE, Breyer BN. Comparison of complication rates related to male urethral slings and artificial urinary sphincters for urinary incontinence: national multi-institutional analysis of ACS-NSQIP database. Int Urol Nephrol 2016;48: 1571-6. 